is grudgingly paid by the guardians, though only one half of it comes out of the pockets of the ratepayers. To keep up this state of things has taken the most determined will and perseverance, and the rigid avoidance of every kind of enjoyment; and yet after all, nothing but insult and annoyance are poured upon me by those who consider themselves masters of all the uniom officers. I look mpon it as a great grievance that the union medical officers have to act under the relieving officers, especially such a specimen of humanity as I have to act under, a most inproper person, yet supported and encouraged by the guardians, who know right well of his peccations. Just now, I am labouring under the annoyance of an attempt to deprive me of the workhouse midwifery fees. I wish some of your correspondents would give me information on this subject. I believe it is the rule not to pay midwifery fees to a medical officer residing in the workhouse; but where the medical officer does not reside in the workhouse, then the rule is to pay for these cases. I have been nearly all day and all night in anxious attendance upon a case of placenta previa, and where it was an arm presentation. Now, if $I$ am to get no fee for this case, what a position I am placed in.

The three principles pointed out by the Convention of Poorlaw Medical Officers are right, as far as they go, yet there are other principles equally urgent. For instance, the half of the salaries comes out of the Consolidated Fund, this is so far good; how much better would it be if the whole came out of the fund, and the payments made, not through the guardians, who in a general way think the union medical officers ought to work for nothing, as they (the guardians) do the union work for nothing. I have heard them use this argument. They forget to ask how they would like to ply their usual trades for nothing. Let the union medical officers be paid as other government officers. As a general rule, there never can be much knowledge of union business amongst the guardians, they are so often changing; each annual election brings fresh hands in, only to change again at the next election. Yet to this little knowledge of poor-law matters the officers have to submit. I have seen projects carried, and upset almost as soon as carried. I say again, there never can be much knowledge of poor-law matters amongst poor-law guardians; they have neither minds to comprehend the complications, nor manners to administer them when comprehended.

June, 1854 .

$$
\text { I am, Sir, your obedient servant, }
$$

A Poop-liw Medical Officer.

\section{THE MEDICAL REFORM BILL OF SIR JOHN FORBES.}

$$
\text { To the Editor of THE LANCET. }
$$

SIR,-The praise and censure bestowed respectively on the London College of Physicians and the College of Surgeons of England by MIr. Nunneley, in his letter to Professor Alison, would be more correct if reversed. If the College of Surgeons, by withholding its assent to the Draught Bill of the Provincial Medical and Surgical Association has been the main obstacle to its enactment, I can only say that it has thereby rendered a signal service both to the public and the profession.

By the provisions of this Draught Bill, the candidate who shall have passed the preliminary examination in medicine and surgery before the Board in England, is further required to obtain either the diploma of the membership of the College of Surgeons, granted at the age of twenty-one, or that of the College of Physicians, granted at the age of twenty-six, ere he can be licensed to practise. Ninety-nine out of a hundred will procure that of the College of Surgeons, instead of waiting five years longer for the membership of the College of Physicians. They will consequently pass two examinations in Surgeryviz., the pre'iminary one before the Board, and the confirmatory one before the College; and one only in Medicine-viz., the preliminary one, conferring the certificate of approval, before the Board. Now, it is well known to the public, as well as the profession, how small a portion surgery constitutes of general practice as compared with medicine, and how important therefore it becomes that the general practitioner should possess a respectable medical degree.

The College of Surgeons, anxious to uphold the status as well as the education of the medical and surgical practitioner of England, confers the membership at twenty-one; and as an inducement to higher attainments in surgery, holds out, with the dignity of the fellowship, the privilege of voting for and the eligibility to the Council. How different is the conduct of the College of Physicians, which wishes to have a finger in the pie, and is quite willing to patronize the general practitioner by assisting at his "little go" examination in medicine before the
Board, but shrinks from all further connexion with him, keeps him at a respectable distance, and withholds from him the lowest diploma of the College, by fixing the age for examination at twenty-six; unlike the Edinburgh and other Scotch universities, which confer degrees at the age of twenty-one; "whereby," says Professor Alison, "the mass of general practitioners throughout the country are better elucated than they otherwise would have been; and many of them, beginning to practise at that age, gradually fit themselves for becoming consulting practitioners in a way more beneficial to the public than if they had all attained the age of twenty-six before re. ceiving the highest honours in medicine." The very idea that the future general practitioner may be examined by the London College of Physicians, or by persons appointed by the College, and that, too, within the precincts of the Hall at Pall-mall, has quite dazzled a large body of medical practitioners, who, out of gratitude for so incomprehensible a condescension, are perpetually singing pæans to the College of Physicians, to the infinite amusement, doubtless, of the latter.

We have had enough of this fawning. Let the general practitioners henceforth look to their own interests; let them first test the good feeling of the College of Physicians towards them by asking this plain question, "Will you follow the example of the Scotch universities, and examine for the membership at the age of twenty-one or twenty-two?" Should the answer be in the negative, an application should immediately be made to the Society of Apothecaries, soliciting that body to petition the Legislature for a new charter of incorporation, under the title of a College of Medicine, or of Medical Practitioners, giving the privilege to all its members of voting for the election of the Council, and leaving the examination in Surgery to the College of Surgeons as at present.

With such an arrangement as this, or an examination for the membership before the College of Physicians at the age of twenty-one or twenty-two, the Draught Bill of Sir John Forbes, which is unquestionably the best that has yet been proposed, would be most acceptable to the great body of the profession, and would readily pass into a law.

I remain, Sir, your obedient servant,

Much Wenlock, June 13, 1854. W. P. BRookes, M.R.C.S.E.

** As Sir John Forbes has not sent a copy of his Bill for publication in THe LANCET, it is probable that he considers his measure not sufficiently matured for its being submitted to the examination of the general body of the profession. We may state at this time that we consider his mode of constituting the Council to be decidedly objectionable.-ED. L.

\section{THE MEDICAL PROFESSION AND LIFE ASSURANCE COMPANIES.}

To the Editor of The LANCET.

SiR,-When I call the attention of the profession to the last stereotyped paragraph in the printed circulars of all the nonpaying insurance offices respecting secresy, it will not condemn me for the strong language used in the following reply (on my part equally stereotyped) just given to the secretary to the Norwich Union Insurance Office.

The profession and yourself have long fought the same battle with some success; but a kind of guerilla warfare continues, which needs your Wellingtonian and our tactics before we can entirely conquer the enemy in the brushwood and mountain fastnesses of his unholy retreats.

If every other medical man would but continue unswervingly this spirited combat, non-paying insurance offices would in a very few years be considered by the next generation of medical men as myths, to the Frankenstein of which we have been the Sibyls of Endor.

Newport, May, $18 \tilde{5}$ t.

I remain, Sir, your obedient servant,

\section{W. W. Morgar.}

Newport, Monmonth, April 24th, 1854.

SrR, - In declining the certification of Miss - - 's health without a fee, I feel it my duty to give my reasons, as I have done on similar occasions to other offices, and to add that when that fee is refused, I always recommend my patients to insure in one of the more liberal fee-paying establishments.

The morality conveyed in the last paragraph of your printed circular is one fit only to be addressed to an apprehended burglar, with the view of coaxing him to turn approver, opposite which I have invariably written a sentiment of scorn or sarcasm, just as then prompted by my feelings. 